\title{
PROPOSTA DE INDICADORES DE COOPERAÇÃO NA GESTÃO COMPARTILHADA DE RESÍDUOS SÓLIDOS
}

\section{Proposal of Cooperation Indicators in the Shared Management of Solid Waste}

\author{
Greg Jordan Alves Silva \\ Mestre em Políticas Públicas pela Univ. Federal do Paraná. Prof. Colab. \\ do Dep. de Adm. da Univ. Estadual do Centro Oeste. Paraná. Brasil. \\ e-mail:greg.unilab@hotmail.com
}

\section{Huáscar Fialho Pessali}

Docente do Dep. de Economia e do Programa de Pós-Graduação em Políticas Públicas. Universidade Federal do Paraná. Paraná. Brasil. e-mail:pessali@ufpr.br

\section{RESUMO}

A Política Nacional de Resíduos Sólidos (BRASIL, 2010) orienta que governos, empresas e sociedade civil se responsabilizem cooperativamente pelos planos de gerenciamento. Nesse sentido, o trabalho que segue tem como intuito propor um instrumento integrado de avaliação para mensurar e classificar o grau de cooperação entre atores envolvidos na gestão compartilhada de resíduos sólidos. Baseando-se num cruzamento entre a literatura sobre cooperação na gestão pública e os debates teóricos e legais sobre a questão dos resíduos sólidos, foram elaborados 19 indicadores divididos em quatro dimensões da cooperação: cognitiva, operacional, relacional e político-institucional, utilizáveis tanto para avaliação em níveis locais de gestão (municípios, microrregiões, etc.) quanto para avaliação dos responsáveis (atores governamentais, atores sociais e atores econômicos). Os indicadores propostos fornecem aos gestores uma visão mais clara sobre a estrutura de gestão compartilhada de resíduos sólidos, permitindo que possam ser planejadas ações pontuais a fim de garantir a parceria entre os setores.

Palavras-chave: cooperação; gestão compartilhada; resíduos sólidos; indicadores.

\section{ABSTRACT}

The National Solid Waste Policy (BRASIL, 2010) directs governments, companies and civil society to take cooperative responsibility for management plans. In this sense, the work that follows aims to propose an integrated evaluation instrument to measure and classify the degree of cooperation between actors involved in shared solid waste management. Based on a cross-reference between the literature on cooperation in public management and the theoretical and legal debates on the issue of solid waste, 19 indicators were elaborated, divided into four dimensions of cooperation: cognitive, operational, relational and political-institutional. (municipalities, microregions, etc.) and for the evaluation of those responsible (government actors, social actors and economic actors). The proposed indicators provide managers with a clearer picture of the shared waste management structure, allowing timely actions to be planned to ensure partnership between sectors.

Keywords: cooperation; shared management; solid waste; indicators. 


\section{INTRODUÇÃO}

A questão dos resíduos sólidos é um dos principais problemas da sociedade urbana da atualidade. As dificuldades em relação à sua gestão estão longe de ser um ônus exclusivo do Estado e da sua estrutura, considerando que desde a geração até a destinação final os diversos atores sociais acumulam responsabilidade sobre tais resíduos. Nesta lógica, é esperado que diversas políticas públicas passem a depender de um comportamento cooperativo de toda a sociedade.

Uma gestão de resíduos sólidos (GRS) pode ser entendida, grosso modo, como a operacionalização dos serviços de coleta e destinação do lixo. Todavia, uma versão integrada contempla a coleta seletiva, a destinação em aterros sanitários sustentáveis, programas de educação ambiental (com foco na redução, reciclagem e reutilização) e ampla articulação entre governos, empresas e cidadãos.

No nível institucional, formulou-se no Brasil a Politica Nacional de Resíduos Sólidos (PNRS), através da Lei Federal no 12.305/2010 (BRASIL, 2010), que traz em seu corpo princípios e objetivos que emergem como uma série de inovações na gestão dos resíduos sólidos, como o desenvolvimento sustentável, a cooperação e o compartilhamento de responsabilidades entre o setor público, a iniciativa privada e a sociedade civil. A fim de propor uma gestão compartilhada e a cooperação, a lei estabelece dois princípios, contidos respectivamente no artigo $5^{\circ}$ e no artigo $6^{\circ}$.

A cooperação na gestão das políticas e serviços públicos surge como estratégia para a busca da eficácia e da efetividade das ações governamentais, contudo, sabe-se que na prática, os agentes estatais são os mais responsabilizados pelo desenvolvimento das políticas e dos serviços, inclusive pelos eventuais fracassos. Nesse sentido, o objetivo desse artigo é propor um instrumento integrado de indicadores para mensurar e classificar o grau de cooperação entre atores envolvidos na gestão de resíduos sólidos.

A presente proposta de indicadores tem a relevância de abrir caminhos para a avaliação de processos de implementação de políticas públicas que são norteados por princípios de cooperação e compartilhamento de responsabilidades, como o caso da PNRS. Na prática, a intenção é apresentar um ferramental que sirva para identificar os pontos críticos que impedem a cooperação efetiva.

Além dessa introdução, serão explanados na próxima sessão os aspectos teóricos sobre a cooperação no âmbito das políticas públicas. Em seguida será mostrado o percurso metodológico para a construção da matriz de indicadores. Na parte dos resultados serão apresentados e discutidos os indicadores propostos e a lógica de aplicação. Por fim, serão feitas as conclusões.

\section{COOPERAÇÃO EM POLÍTICAS PÚBLICAS}

De forma geral, cooperação tem um sentido de trabalho em comum, de colaborar mutuamente. $\mathrm{O}$ tema da cooperação está presente em vários campos do saber, tais com a ciência política, administração pública, a economia, relações internacionais, psicologia, dentre outros. Como denominador comum a esses campos, está a noção de que a cooperação permite a interação e estimula a confiança entre os diversos agentes num espaço de busca de benefícios e vantagens mútuas (AXELROD, 1986; RING; VAN DE VEN; 1994; LUNDIN, 2007b).

A partir de um ponto de vista reformador, Axelrod (1986) desenvolve três categorias que norteiam a promoção da cooperação através da transformação do próprio ambiente estratégico, a saber: a) valorizar a importância do futuro em comparação com o presente; b) modificar os retornos atribuídos aos jogadores (ou agentes); e c) ensinar aos agentes os valores, ações e habilidades que sirvam para a promoção da cooperação. O mesmo autor expõe cinco mecanismos para promover a cooperação, com base nas categorias citadas anteriormente: a) magnificar as projeções sobre o futuro; b) modificar os incentivos e sanções; c) ensinar as pessoas a se preocuparem umas com as outras; d) ensinar a reciprocidade; e e) melhorar a capacidade de reconhecimento (AXELROD, 1986). As contribuições de Axelrod foram fundamentais e deram sustento a diversos estudos posteriores sobre a prática da cooperação.

Smith, Carroll, e Ashford (1995) apontam que existem pelo menos duas maneiras em que as relações de cooperação podem ocorrer: informalmente 
ou formalmente. A cooperação do estilo informal abrange arranjos adaptáveis em que as normas de comportamento, em detrimento das obrigações contratuais determinam as contribuições das partes envolvidas. No modo formal, a cooperação é caracterizada por obrigações contratuais e estruturas formais de controle, como organogramas de projetos que podem forçar as pessoas a trabalhar em conjunto e estruturas e processos organizacionais que podem detalhadamente definir como os departamentos e grupos devem funcionar (SMITH; CARROLL; ASHFORD, 1995).

Além das relações formais, o tipo de cooperação também pode variar de acordo com a forma que os agentes estão relacionados. Smith, Carroll, e Ashford (1995) explicam que numa ligação vertical, a cooperação pode ocorrer entre indivíduos, grupos e organizações de diferentes níveis, ou seja, entre superiores e subordinados. No caso das relações cooperativas horizontais, os envolvidos podem cooperar em uma tarefa comum, até mesmo quando são concorrentes do mesmo ramo. A principal diferença entre as ligações verticais e as ligações horizontais está no nível de interdependência, pois se apresenta de forma mais clara e direta em ligações verticais (SMITH; CARROLL; ASHFORD, 1995). Usufruindo dessa tipologia, a cooperação na gestão compartilhada de resíduos sólidos pode ser considerada horizontal já que na relação entre atores governamentais, econômicos e cidadãos, não há uma estrutura hierárquica instituída.

Lundin (2007a) discute sobre os custos da cooperação. Para esse autor, tais custos aumentam à medida que a complexidade da cooperação aumenta. Defende ainda que a cooperação é um processo dinâmico e que as decisões e atividades dentro de uma arena não são independentes uns dos outros, ou seja, sempre há complexidade e consequentemente, custos.

No setor público, a cooperação pode ser entendida como as interações entre os agentes com vistas à resolução de problemas públicos, trabalhando em conjunto ao invés de individualmente (SMITH; CARROLL; ASHFORD, 1995). Há uma variedade de formatos em que a cooperação pode acontecer no setor público, tais como: cooperação intergovernamental, cooperação interorganizacional, cooperação interprofissional, coprodução de serviços públicos, gestão compartilhada, dentre outros.
É possível apontar que no âmbito da gestão de serviços e políticas públicas a cooperação possui dois sentidos. O primeiro refere-se ao comportamento organizacional, Smith, Carroll, e Ashford (1995) afirmam que a maioria das definições sobre a cooperação dão ênfase no processo pelo qual os indivíduos, grupos e organizações se unem, interagem e formam relacionamentos psicológicos para ganhos ou benefícios mútuos. O segundo sentido emerge como um instrumento/estratégia de implementação de políticas públicas, assim, conforme Lundin (2007a), os quadros teóricos contemporâneos explicam que o sucesso ou fracasso na fase da implementação das políticas públicas tem a ver com a forma com a qual as relações interorganizacionais são geridas.

No desenho das relações entre instituições públicas, Weiss (1987) atribui que a cooperação intergovernamental acontece por algumas razões: para obter mais recursos, atender às normas e valores, obter vantagem política, resolver problemas, reduzir as incertezas e obedecer a obrigações legais. Nessa mesma linha, Lundin (2007 b) defende que certas decisões políticas são fáceis de serem tomadas e podem ser responsabilidade quase exclusiva de uma administração pública unitária e, por isso, a etapa da execução das políticas e serviços públicos é o momento de maior carência de cooperação, por ser normalmente a fase mais complicada e que envolve muitos e variados participantes.

A cooperação no setor público também é vista através do prisma da participação política. Whitaker (1980) considera que a cooperação só é pura e legítima por parte dos cidadãos quando acontece de forma voluntária, como um exercício de consciência cidadã. O contrário, ou seja, quando os cidadãos agem de acordo com os objetivos do serviço público porque temem represálias ou porque se habituaram a colaborar sem contestação, suas ações não constituem uma cooperação.

No contexto de uma nova esfera pública, a construção de um "sistema poliárquico" (DAHL, 1997) é resultado não apenas de um deslocamento do nível central para o nível local, mas também do Estado para a sociedade. A decorrência de tal processo somado ao fortalecimento da sociedade civil direciona-se na concepção de modelos inovadores de 
gestão compartilhada de políticas públicas (FLEURY; OUVERNEY, 2007).

Ainda que do ponto de vista político a cooperação seja percebida como algo voluntário, as instituições públicas, quando lhes convêm, podem orientar ou estimular as práticas de cooperação. Dessa forma, Weiss (1987) aponta três passos para construir programas de cooperação: 1) identificação de um problema que seja comum e que possa ser resolvido por cooperação; 2) disponibilização recursos diversos para as atividades de cooperação e; 3 ) garantia que haja capacidade institucional (mecanismos legítimos, rotinas, etc.) para a criação de programas de cooperação. Pode-se considerar que os passos propostos por Weiss (1987) reduzem, relativamente, um processo que nem sempre é simples. Todavia, possuem a conveniência de serem adaptados, haja vista que tais programas de cooperação podem surgir em diferentes formatos, como os que são referidos a seguir.

\subsection{Responsabilidade compartilhada e coprodução de serviço público}

Na gestão compartilhada de políticas públicas, a noção de cooperação emerge como um princípio norteador. Num enquadramento entre a literatura sobre a prática cooperativa e as orientações da Política Nacional de Resíduos Sólidos, o compartilhamento de responsabilidades na gestão das políticas públicas surge como sinônimo de coprodução de serviço público.

A coprodução do bem público pode ser definida como um processo que envolve a "participação ativa e direta do cidadão nos processos de elaboração, desenho, implementação e avaliação das políticas públicas voltadas ao interesse público e, em última instância, à construção do bem comum" (RIBEIRO; SALM; MENEGASSO, 2007, p. 232). Essa participação transcende o debate da arena de decisão e se figura como uma reestruturação das instituições, dando um novo sentido à prestação de serviços públicos, por isso, o modelo ideal de coprodução concebe o envolvimento dos cidadãos, do Estado e inclusive atores oriundos do mercado que, numa relação de mútua confiança, compartilham responsabilidades na produção de bens e serviços públicos. (MATTIA; ZAPPELLINI, 2014).

Whitaker (1980) aponta que três tipos de ação correspondem à coprodução na gestão pública: a) quando o cidadão solicita a ajuda de agentes públicos; b) quando os cidadãos fornecem, de forma colaborativa, assistência aos atores governamentais na execução dos programas da agência; c) quando há interação entre os diferentes agentes, no intuito de negociar o direcionamento e as expectativas de cada serviço. No caso da PNRS, a coprodução corresponde ao terceiro tipo, contudo envolve uma relação tripartite.

Como em qualquer relação de cooperação, a responsabilidade compartilhada e a coprodução predispõem um caráter comportamental, assim, exige que os cidadãos e demais agentes, devam estar dispostos a reconhecer a legitimidade das políticas públicas em que são responsáveis pela gestão e devem estar no mínimo dispostos a falar e a ouvir (WHITAKER, 1980). A finalidade sempre está relacionada a uma mudança positiva e efetiva na prestação dos serviços, portanto Whitaker (1980) considera que o compartilhamento ou participação na transformação recíproca de expectativas e ações entre os agentes é um instrumento para tais mudanças positivas.

A partir das ideias dos atores aqui citados, aliadas a outros trabalhos empíricos e teóricos sobre a temática, segue abaixo um enquadramento dimensional que enfatiza as principais concepções e implicações da cooperação, agrupando-as com base em seus níveis funcionais na gestão das políticas públicas.

As dimensões expostas no quadro acima nortearam a construção dos indicadores, as perguntas chave, os respectivos descritores e notas que serão apresentados em sessões posteriores. 
Quadro 1 Dimensões da cooperação

\begin{tabular}{l|l|l}
\hline \multicolumn{1}{c|}{ Dimensão } & \multicolumn{1}{|c}{ Fundamento } & \multicolumn{1}{c}{ Principais Referências } \\
\hline Cognitiva & $\begin{array}{l}\text { A cooperação surge de hábitos e comportamentos } \\
\text { e é externalizada a partir da noção de problemas em } \\
\text { comum e da percepção da necessidade da ação colabo- } \\
\text { rativa e recíproca. }\end{array}$ & $\begin{array}{l}\text { Lundin (2007a); Hawkins (2010); Munhoz; Ferreira (2012); } \\
\text { Kolk (1998); Axelrod (1986); Whitaker (1980) }\end{array}$ \\
\hline Operacional & $\begin{array}{l}\text { As práticas cooperativas partem e são potencializadas } \\
\text { por obrigações contratuais ou mecanismos operacio- } \\
\text { nais formais ou informais de incentivos. }\end{array}$ & $\begin{array}{l}\text { Munhoz; Ferreira (2012); Rocha; Faria (2004); Smith; } \\
\text { Carroll; Ashford (1995) }\end{array}$ \\
\hline Relacional & $\begin{array}{l}\text { A cooperação se estabelece nas relações sociais a partir } \\
\text { das aspirações em comum e vigora através de elemen- } \\
\text { tos que nascem das relações interpessoais e interorgani- } \\
\text { zacionais, como a comunicação, a confiança e a parceria. }\end{array}$ & $\begin{array}{l}\text { Santiago; Dias (2012); Whitaker (1980); Lundin (2007b); } \\
\text { Smith; Carroll; Ashford (1995); Lundin (2007b); Ring; Van } \\
\text { ferreira (2012); }\end{array}$ \\
\hline Política-Institucional & $\begin{array}{l}\text { Em algumas ocasiões a cooperação é imputada por } \\
\text { obrigações legais ou é impulsionada ou pela percepção } \\
\text { de vantagens políticas ou por características específicas } \\
\text { de arranjos institucionais/locais. }\end{array}$ & $\begin{array}{l}\text { Weiss (1987); Ring; Van de Ven (1994); Ribeiro; Salm; Me- } \\
\text { negasso (2007); Smith; Carroll; Ashford (1995); Abrucio; } \\
\text { Filippim; Dieguez (2013); } \\
\text { Lundin (2007b); Axelrod (1986) }\end{array}$ \\
\hline
\end{tabular}

Fonte: Elaborado pelos autores (2017).

\section{GESTÃO COMPARTILHADA DE RESÍDUOS SÓLIDOS}

A Política Nacional de Resíduos Sólidos estabelece em dois de seus princípios a cooperação e a gestão compartilhada dos resíduos sólidos. O artigo $6^{\circ}$ prevê a cooperação entre as diferentes esferas do poder público, o setor empresarial e demais segmentos e o artigo $5^{\circ}$ institui a responsabilidade compartilhada pela vida dos produtos (BRASIL, 2010).

Outras iniciativas, com outras nomenclaturas, instituíram-se na perspectiva de desenvolver a prática da gestão compartilhada. Orsi (2006), em seu estudo sobre a gestão participativa dos resíduos sólidos afirma que a gestão participativa constitui-se como forma legítima e democrática de gerir o que é público, podendo gerar atitudes positivas e comprometidas com seu espaço e, portanto a busca do chamado desenvolvimento sustentável deve considerar, além de outros elementos, a participação efetiva da sociedade civil organizada no planejamento e gestão do território.

No que cerne à gestão dos resíduos sólidos, Demajarovic, Besen, Rathsam (1995) apontam alguns benefícios trazidos pelo modelo de gestão compartilhada. Para eles, incluir atores sociais en- volvidos, como os catadores de lixo, almeja valorizar o trabalho, que promove o resgate da cidadania e a inclusão social. Outro benefício apontado pelos autores diz respeito à "garantia de maior quantidade e de melhor qualidade do material reciclável, contribuindo para aumentar as oportunidades de venda direta às indústrias por melhores preços" (p.7), que inclui os atores econômicos.

Um modelo de gestão compartilhada de políticas públicas retira do setor governamental o ônus antes exclusivo a ele, transferindo a responsabilidade para os demais setores. Reportando-se a lei e seguindo a proposta metodológica desse estudo, a gestão compartilhada dos resíduos sólidos conta, simultânea e cooperativamente com a participação dos atores econômicos (campo empresarial), dos atores sociais (sociedade civil) e dos atores governamentais (poder público). A seguir serão explicadas a atuação e a relevância de cada um desses atores no exercício da gestão.

\subsection{Atores Sociais}

Não é da última década o interesse de grupos (políticos e sociais) em institucionalizar a participação da população nas decisões públicas, na gestão e no controle das políticas públicas, pois desde a 
promulgação da Constituição Federal Brasileira de 1988, que se discute, se experimenta e se estabelece mecanismos de participação social.

Em algumas ocasiões, a sociedade civil exerce o papel mais importante, pois através de suas práticas e comportamentos é capaz de solucionar problemas antes destes se tornarem demandas para o Estado. Sobre isso, Orsi (2010) afirma que a participação social se constitui num importante elemento para melhoria dos serviços relacionados à gestão dos resíduos sólidos, isso porque ela pode deixar de ser agente passivo do processo de planejamento e gestão e receptora dos problemas e transforma-se em agente ativo modelador de soluções.

A atuação dos atores sociais quanto à gestão dos resíduos sólidos direciona-se por duas premissas, a do cumprimento de responsabilidades (caráter técnico) e do controle social (caráter político). No sentido técnico, as atribuições para esses atores são muito claras e abrangem a redução da geração de resíduos, a disposição adequada dos resíduos gerados e sua disponibilização para coleta convencional ou seletiva (art. 35, PNRS). Já na premissa do controle social, "pode auxiliar na fiscalização, participar no processo de gestão, e ser agente imprescindível de pressão sobre o poder público e sobre os atores econômicos" (ORSI, 2010 p. 83). Todavia, essa responsabilidade de fiscalizar requer da população o mínimo de conhecimento sobre a política nacional, bem como sobre os planos municipais e estaduais de resíduos sólidos.

\subsection{Atores Econômicos}

A Política Nacional de Resíduos Sólidos inova ao incorporar os agentes econômicos como corresponsáveis pela gestão de uma política pública. A associação entre o poder público e o setor privado para a execução de serviços públicos ou obras públicas já é uma prática corriqueira, como o caso das conhecidas Parcerias-Público-Privadas (PPP). Contudo, no caso na PNRS, não se trata institucionalmente de uma PPP, mas de uma oneração dada ao setor privado pelos resíduos por ele gerado.

Um dos princípios da PNRS, citado no artigo $6^{\circ}$, o princípio do "poluidor -pagador" apregoa sobre a responsabilidade dos setores produtivos, sendo estes tidos como poluidores e causadores de externalida- des ambientais negativas (MOREIRA, 2011). Com isso, surge a finalidade desse princípio na lei, que seria o uso de instrumentos jurídicos que levem a uma interpretação de responsabilização ambiental pós-consumo, de modo a garantir a todos o direito ao meio ambiente equilibrado (BRANDÃO; OLIVEIRA, 2012).

De acordo com Romani e Segala (2014), as atribuições inerentes ao setor empresarial referem-se de forma geral ao recolhimento dos produtos após o uso, além de priorizar processos de produção, distribuição e comercialização que gerem a menor quantidade possível de resíduos e que possibilitem o uso de matérias-primas oriundas do beneficiamento dos materiais recicláveis. Um estudo do Instituto Ethos, de São Paulo, sobre a PNRS, considerou que um dos principais mecanismos da política, a logística reversa, é tida como um instrumento de desenvolvimento econômico e social, estruturado a partir de um "conjunto de ações, procedimentos e meios destinados a viabilizar a coleta e a restituição dos resíduos sólidos ao setor empresarial" (INSTITUTO ETHOS, 2012, p.13). Nesse sentido, a responsabilidade primordial das empresas é incorporar integralmente em seus processos e produtos um leque de ações colaborativas e sustentáveis.

\subsection{Atores Governamentais}

O setor público, como o produtor por excelência de políticas públicas (SOUZA, 2006), é o ator mais esperado em relação à implementação da PNRS. Este setor deve estabelecer as linhas gerais de funcionamento da política, regulando e fiscalizando a ação dos atores sociais e econômicos no processo de gestão, deve também estimular e tornar viável a participação do poder econômico e da sociedade civil em todas as iniciativas do setor público (ORSI, 2010).

No que cerne aos municípios de pequeno porte, Heber e Silva (2014) partem do pressuposto de que a gestão compartilhada e a regulação de estímulo para a formação de mecanismos intermunicipais de cooperação é ameaçada pela pequena capacidade gerencial e o baixo volume orçamentário dos municípios, que consequentemente inviabilizam ações efetivas de limpeza urbana e destinação final dos resíduos tecnicamente e socialmente adequados. 
$\mathrm{O}$ artigo $36^{\circ}$ da PNRS define as imputações do poder público perante a gestão compartilhada e integrada dos resíduos sólidos:

I - adotar procedimentos para reaproveitar os resíduos sólidos reutilizáveis e recicláveis oriundos dos serviços públicos de limpeza urbana e de manejo de resíduos sólidos; II - estabelecer sistema de coleta seletiva; III - articular com os agentes econômicos e sociais medidas para viabilizar o retorno ao ciclo produtivo dos resíduos sólidos reutilizáveis e recicláveis oriundos dos serviços públicos de limpeza urbana e de manejo de resíduos sólidos; IV - realizar as atividades definidas por acordo setorial ou termo de compromisso, mediante a devida remuneração pelo setor empresarial; V - implantar sistema de compostagem para resíduos sólidos orgânicos e articular com os agentes econômicos e sociais formas de utilização do composto produzido; VI - dar disposição final ambientalmente adequada aos rejeitos oriundos dos serviços de limpeza urbana e de manejo de resíduos sólidos.

Os agentes públicos de implementação (prefeitos, secretários e burocratas) emergem como facilitadores na execução da PNRS, isso porque são detentores de maior respaldo jurídico, de maior disponibilidade orçamentária e de espaços consolidados para a criação de incentivos com finalidades atreladas a PNRS, comparando-os com os outros agentes.

\section{CAMINHO METODOLÓGICO PARA A CONSTRUÇÃO DA MATRIZ DE INDICADORES}

O primeiro momento dessa proposta se deu com o levantamento bibliográfico ${ }^{1} \mathrm{em}$ bases de dados nacionais e internacionais sobre o tema "cooperação" e "cooperação em políticas públicas" ${ }^{2}$, a fim de encontrar os determinantes e demais elementos da cooperação, para o embasamento dos indicadores. A partir da exploração e análise dos artigos, foram destacadas quatro dimensões práticas da cooperação (expostas na sessão dois), que foram o ponto de partida para a construção dos indicadores.

Costa e Castanhar (2003) consideram que os indicadores são formas específicas de operacionalização de critérios de avaliação, pois constituem medidas indiretas, ou seja, que devem ser calculadas a partir da identificação e quantificação dos resultados obtidos. No âmbito das políticas públicas, "os indicadores apontam, indicam, aproximam, traduzem em termos operacionais as dimensões sociais de interesse definidas a partir de escolhas teóricas ou políticas realizadas anteriormente" (JANNUZZI, 2005, p. 138). Em relação à sua utilidade, os indicadores são importantes instrumentos de gestão, já que fornecem ao administrador público os pontos cruciais dos sistemas e processos, o monitoramento de situações que devem ser mudadas, incentivadas ou potencializadas ao longo do processo de intervenção até o alcance das metas previstas (MINAYO, 2009). Na presente proposta, os indicadores apresentam importância tanto como ferramenta de gestão como técnica para a análise da implementação da Política Nacional de Resíduos Sólidos.

No QUADRO 2 estão dispostos os 19 indicadores de cooperação na gestão compartilhada dos resíduos sólidos em suas correspondentes dimensões, bem como as principais referências que argumentam sobre o papel dos respectivos indicadores na promoção da cooperação.

Para a construção dos indicadores foi feito um cruzamento entre as dimensões (criadas através da pesquisa bibliográfica) e as ações dos atores perante a gestão dos resíduos sólidos, descritos na PNRS. Os parâmetros que compõem a proposta de indicadores de cooperação para a GRS são: dimensão prática da cooperação, indicador, questão-chave, descritor e nota. O desenho estrutural da proposta de indicadores, apresentado na próxima sessão, se baseou na matriz de indicadores de sustentabilidade publicada por Santiago e Dias (2012), adaptada para o presente caso, observando-se suas especificidades.

As questões chave presentes em cada indicador não consistem em um questionário, mas num suporte, uma compreensão objetiva do pesquisador, depois de decorrida a coleta dos dados. Vale ressaltar que na proposta de cada agente haverá um grupo de questões iguais ou diferentes, tendo em vista que cada um tem uma atuação específica na gestão compartilhada, mas a critério de comparação, os indicadores são os mesmos.

1 Levantamento bibliográfico nas seguintes bases de dados: Scielo Brasil, Google Acadêmico e o Portal da Informação da Universidade Federal do Paraná (www.portal.ufpr.br).

2 Busca em Português e em Inglês ("cooperation", "cooperation and public policy"). 
Quadro 2 Indicadores de cooperação para a gestão compartilhada de resíduos sólidos

\begin{tabular}{|c|c|c|c|}
\hline Dimensão & No & Indicadores & Referências \\
\hline \multirow[t]{4}{*}{ Cognitiva } & 1 & Conhecimento da política & Lundin (2007a); Hawkins (2010); Munhoz; Ferreira (2012) \\
\hline & 2 & Noção da problemática & Hawkins (2010); Kolk (1998) \\
\hline & 3 & Percepção da necessidade de cooperação & Axelrod (1986); Whitaker (1980) \\
\hline & 4 & Reconhecimento da responsabilidade mútua & Whitaker (1980); Axelrod (1986) \\
\hline \multirow[t]{4}{*}{ Operacional } & 5 & Cumprimento da responsabilidade & Munhoz; Ferreira (2012); Lei 12.305 (2010) \\
\hline & 6 & Formalização da cooperação & Rocha; Faria (2004) \\
\hline & 7 & Mecanismos de incentivo à cooperação & Smith; Carroll; Ashford (1995) \\
\hline & 8 & Criatividade e experimentação & Rocha; Faria (2004) \\
\hline \multirow[t]{6}{*}{ Relacional } & 9 & Partilha & Matuda; Aguiar; Frazão (2013) \\
\hline & 10 & Intersetorialidade ou Parceria & Santiago e Dias (2012). \\
\hline & 11 & Comunicação & Whitaker (1980); Matuda; Aguiar; Frazão (2013); \\
\hline & 12 & Confiança & Lundin (2007b); Smith; Carroll; Ashford (1995) \\
\hline & 13 & Congruência de aspirações & Lundin (2007b); Ring; Van de Ven (1994) \\
\hline & 14 & Empoderamento e autonomia & Matuda; Aguiar; Frazão (2013); Munhoz; Ferreira (2012) \\
\hline \multirow[t]{5}{*}{ Política- Institucional } & 15 & Percepção de vantagens políticas & Weiss (1987); Ring; Van de Ven (1994) \\
\hline & 16 & Obrigações legais & Weiss (1987) \\
\hline & 17 & Participação nos processos decisórios & Lei 12.305 (2010); Ribeiro; Salm; Menegasso (2007) \\
\hline & 18 & Elementos institucionais para a cooperação & Smith; Carroll; Ashford (1995); Abrucio; Filippim; Dieguez, (2013) \\
\hline & 19 & Cultura institucional de cooperação & Lundin (2007) \\
\hline
\end{tabular}

Fonte: Elaborado pelo autor (2017)

\section{RESULTADOS}

As propostas de indicadores de cooperação estão dispostas nos QUADROS 3, 4 E 5, como já mencionado os diferentes atores possuem responsabilidades diferentes e maneiras distintas de cooperar e influenciar a gestão. Nesse sentido, a proposta é dispor indicadores que além de uma avaliação, permitam fazer comparações tanto entre atores como entre dimensões.

No QUADRO 3, estão dispostos os indicadores e demais parâmetros referentes ao papel dos atores governamentais, tanto técnicos quanto políticos, na gestão de resíduos sólidos. 
Quadro 3 Proposta de indicadores e parâmetros para análise dos agentes governamentais

\begin{tabular}{|c|c|c|c|c|}
\hline Dimensão & Indicador & Questão-chave & Descritor & Nota \\
\hline \multirow[t]{15}{*}{ Cognitiva } & \multirow[t]{3}{*}{ (1) Conhecimento da política } & \multirow[t]{3}{*}{ Conhece a PNRS? (1a) } & Conhece & 1 \\
\hline & & & Já ouviu falar & 0,5 \\
\hline & & & Não conhece & 0 \\
\hline & \multirow{6}{*}{$\begin{array}{l}\text { (2) Noção da problemática Nota do } \\
\text { indicador } 2=(2 a+2 b) / 2\end{array}$} & \multirow{3}{*}{$\begin{array}{l}\text { Considera a questão do lixo um } \\
\text { problema no município? (2a) }\end{array}$} & Sim, muito & 1 \\
\hline & & & Em partes & 0,5 \\
\hline & & & Não ou não sabe opinar & 0 \\
\hline & & \multirow{3}{*}{$\begin{array}{l}\text { Apresenta conhecimento sobre } \\
\text { os impactos negativos do lixo na } \\
\text { sociedade? (2b) }\end{array}$} & Sim, razoável & 1 \\
\hline & & & Pouco & 0,5 \\
\hline & & & Nenhum & 0 \\
\hline & \multirow{3}{*}{$\begin{array}{l}\text { (3) Percepção da necessidade de } \\
\text { cooperação }\end{array}$} & \multirow{3}{*}{$\begin{array}{l}\text { Percebe que a cooperação é } \\
\text { necessária à gestão? (3a) }\end{array}$} & Sim & 1 \\
\hline & & & Parcialmente & 0,5 \\
\hline & & & Não ou não sabe opinar & 0 \\
\hline & \multirow{3}{*}{$\begin{array}{l}\text { (4) Reconhecimento da responsa- } \\
\text { bilidade compartilhada }\end{array}$} & \multirow{3}{*}{$\begin{array}{l}\text { Reconhece a responsabilidade dos } \\
\text { demais na gestão da política? (4a) }\end{array}$} & Sim & 1 \\
\hline & & & Parcialmente & 0,5 \\
\hline & & & Não, ou não sabe opinar & 0 \\
\hline \multicolumn{4}{|c|}{ Subtotal Máximo } & 4 \\
\hline \multirow[t]{16}{*}{ Operacional } & \multirow{9}{*}{$\begin{array}{l}\text { (5) Cumprimento da responsa- } \\
\text { bilidade Nota do indicador } 5= \\
(5 a+5 b+5 c) / 3\end{array}$} & \multirow{3}{*}{$\begin{array}{l}\text { Foi criado o Plano de Gerencia- } \\
\text { mento de Resíduos Sólidos? (5a) }\end{array}$} & Existe & 1 \\
\hline & & & Está em andamento & 0,5 \\
\hline & & & Não existe & 0 \\
\hline & & \multirow[t]{3}{*}{ Frequência da coleta básica (5b) } & Diariamente & 1 \\
\hline & & & Algumas vezes por semana & 0,5 \\
\hline & & & Não existe cronograma & 0 \\
\hline & & \multirow[t]{3}{*}{ Execução da coleta seletiva (5c) } & Existe, e é eficiente & 1 \\
\hline & & & Existe, mas precisa melhorar. & 0,5 \\
\hline & & & Não existe & 0 \\
\hline & \multirow[t]{2}{*}{ (6) Formalização da cooperação } & \multirow{2}{*}{$\begin{array}{l}\text { Existe algum tipo de vínculo formal } \\
\text { para tornar a cooperação uma } \\
\text { prática (6a). }\end{array}$} & Sim & 1 \\
\hline & & & Não & 0 \\
\hline & \multirow{2}{*}{$\begin{array}{l}\text { (7) Instrumentos de incentivo a } \\
\text { cooperação }\end{array}$} & \multirow{2}{*}{$\begin{array}{l}\text { Promove alguma ferramenta para } \\
\text { incentivar a cooperação? (bonifica- } \\
\text { ção, etc). (7a) }\end{array}$} & Sim & 1 \\
\hline & & & Não & 0 \\
\hline & \multirow[t]{3}{*}{ (8) Criatividade e experimentação } & \multirow{3}{*}{$\begin{array}{l}\text { Cria ou experimenta novas ações } \\
\text { ou estratégias para a GRS? (8a) }\end{array}$} & Sim & 1 \\
\hline & & & Parcialmente & 0,5 \\
\hline & & & Não & 0 \\
\hline & & \multicolumn{2}{|l|}{ Subtotal Máximo } & 4 \\
\hline
\end{tabular}




\begin{tabular}{|c|c|c|c|c|}
\hline Dimensão & Indicador & Questão-chave & Descritor & Nota \\
\hline \multirow[t]{30}{*}{ Relacional } & \multirow{9}{*}{$\begin{array}{l}\text { (9) Partilha - Cumprimento da } \\
\text { responsabilidade (sob o ponto de } \\
\text { vista dos atores governamentais). } \\
9=(9 a+9 b+9 c+9 d+9 e+9 f) / 6\end{array}$} & \multirow{3}{*}{$\begin{array}{l}\text { Divulgação do Plano de Gerencia- } \\
\text { mento de Resíduos Sólidos? (9a) }\end{array}$} & Existe e foi divulgado. & 1 \\
\hline & & & Está sendo divulgada a preparação & 0,5 \\
\hline & & & Não & 0 \\
\hline & & \multirow[t]{3}{*}{ Frequência da coleta básica (9b) } & Diariamente & 1 \\
\hline & & & Algumas vezes por semana & 0,5 \\
\hline & & & Não existe cronograma & 0 \\
\hline & & \multirow[t]{3}{*}{ Execução da coleta seletiva (9c) } & Existe, e é eficiente & 1 \\
\hline & & & Existe, mas precisa melhorar & 0,5 \\
\hline & & & Não existe & 0 \\
\hline & \multirow{9}{*}{$\begin{array}{l}\text { (9) Partilha- Cumprimento da } \\
\text { responsabilidade (sob o ponto } \\
\text { de vista dos atores sociais). Nota } \\
\text { do indicador } 9=(9 a+9 b+9 c+- \\
9 d+9 e+9 f) / 6\end{array}$} & \multirow{3}{*}{$\begin{array}{l}\text { Divulgou o Plano de Gerenciamen- } \\
\text { to de Resíduos Sólidos? (9d) }\end{array}$} & Existe e foi divulgado. & 1 \\
\hline & & & Está sendo divulgada a preparação & 0,5 \\
\hline & & & Não & 0 \\
\hline & & \multirow[t]{3}{*}{ Frequência da coleta básica (9e) } & Diariamente & 1 \\
\hline & & & Algumas vezes por semana & 0,5 \\
\hline & & & Não existe cronograma & 0 \\
\hline & & \multirow[t]{3}{*}{ Execução da coleta seletiva (9f) } & Existe, e é eficiente & 1 \\
\hline & & & Existe, mas precisa melhorar & 0,5 \\
\hline & & & Não existe & 0 \\
\hline & \multirow[t]{3}{*}{ (10) Intersetorialidade ou parceria } & \multirow{3}{*}{$\begin{array}{l}\text { Quantas secretarias ou órgãos } \\
\text { públicos estão ligados a questão } \\
\text { dos resíduos sólidos? (10a) }\end{array}$} & Acima de 3 & 1 \\
\hline & & & Entre 2 e 3 & 0,5 \\
\hline & & & Apenas um(a) & 0 \\
\hline & \multirow{6}{*}{$\begin{array}{l}\text { (11) Comunicação. Nota do indica- } \\
\text { dor } 11=(11 a+11 b) / 2\end{array}$} & \multirow{3}{*}{$\begin{array}{l}\text { Dispõe de canal de comunicação? } \\
\text { (11a) }\end{array}$} & Exclusivo para a GRS & 1 \\
\hline & & & No órgão & 0,5 \\
\hline & & & Não existe & 0 \\
\hline & & \multirow{3}{*}{$\begin{array}{l}\text { Divulga o calendário de coleta } \\
\text { básica/ seletiva? (11b) }\end{array}$} & Plena divulgação & 1 \\
\hline & & & Média divulgação & 0,5 \\
\hline & & & Nenhuma divulgação & 0 \\
\hline & \multirow{3}{*}{$\begin{array}{l}\text { (12) Confiança (sob o ponto de } \\
\text { vista dos atores sociais). }\end{array}$} & \multirow{3}{*}{$\begin{array}{l}\text { Acredita que o ator específico } \\
\text { tenha boa vontade e possa se } \\
\text { esforçar para fazer sua parte? (12a) }\end{array}$} & Sim & 1 \\
\hline & & & Parcialmente & 0,5 \\
\hline & & & Não & 0 \\
\hline
\end{tabular}




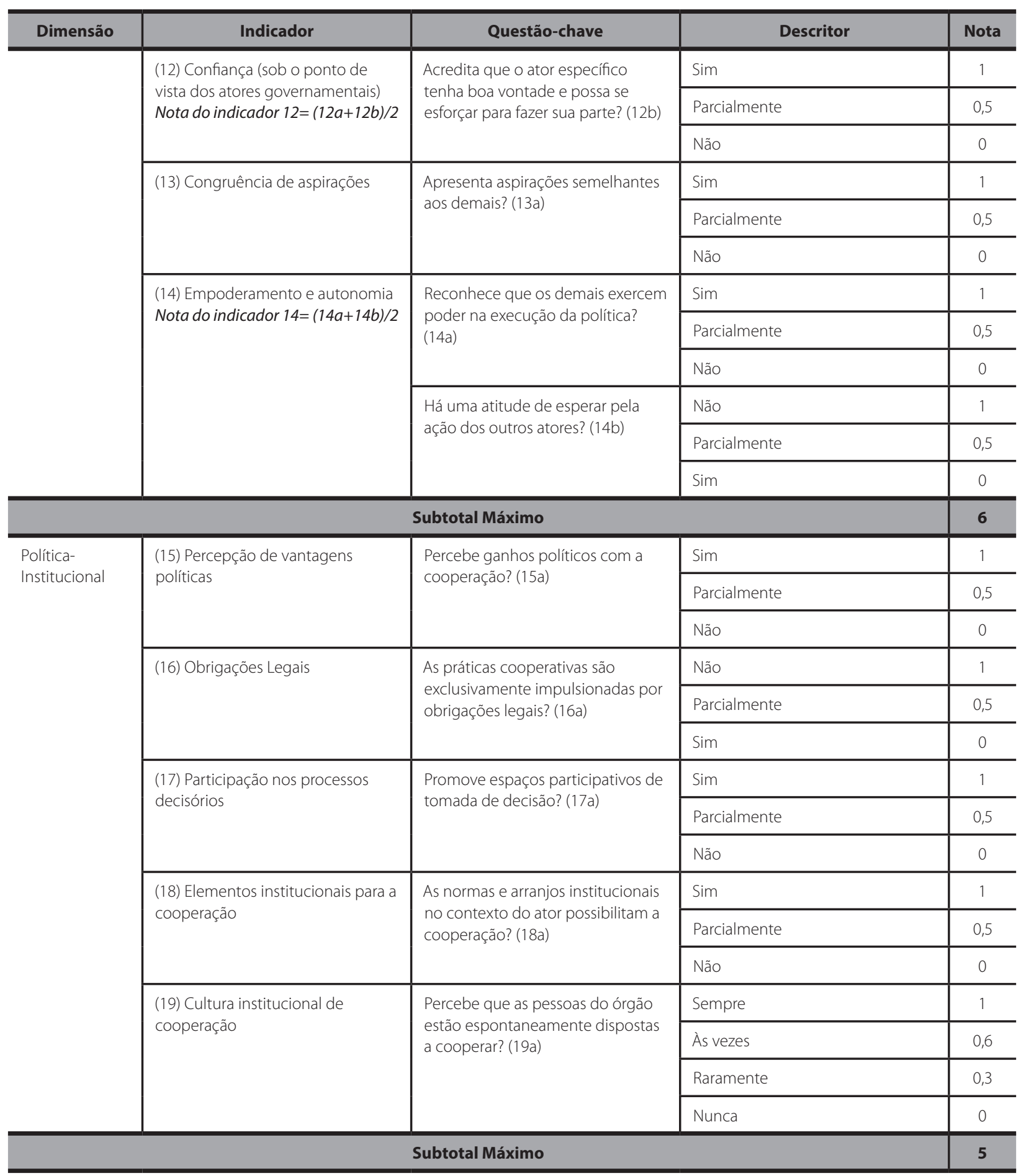

Fonte: Elaborado pelos autores (2017) 
O quadro a seguir apresenta os indicadores que tão compartilhada de resíduos sólidos, evidenciando preconizam a participação da sociedade civil na ges- a ação local por via da iniciativa popular.

Quadro 4 Proposta de indicadores e parâmetros para análise dos agentes sociais

\begin{tabular}{|c|c|c|c|c|}
\hline Dimensão & Indicador & Questão-chave & Descritor & Nota \\
\hline \multirow[t]{15}{*}{ Cognitiva } & \multirow[t]{3}{*}{ (1) Conhecimento da política } & \multirow[t]{3}{*}{ Conhece a PNRS? (1a) } & Conhece & 1 \\
\hline & & & Já ouviu falar & 0,5 \\
\hline & & & Não conhece & 0 \\
\hline & \multirow{6}{*}{$\begin{array}{l}\text { (2) Noção da problemática Nota do } \\
\text { indicador } 2=(2 a+2 b) / 2\end{array}$} & \multirow{3}{*}{$\begin{array}{l}\text { Considera a questão do lixo um } \\
\text { problema no município? (2a) }\end{array}$} & Sim, muito & 1 \\
\hline & & & Mais ou menos & 0,5 \\
\hline & & & Não ou não sabe opinar & 0 \\
\hline & & \multirow{3}{*}{$\begin{array}{l}\text { Apresenta conhecimento sobre os } \\
\text { impactos do lixo? (2b) }\end{array}$} & Sim, muito & 1 \\
\hline & & & Pouco & 0,5 \\
\hline & & & Nenhum & 0 \\
\hline & \multirow{3}{*}{$\begin{array}{l}\text { (3) Percepção da necessidade de } \\
\text { cooperação }\end{array}$} & \multirow{3}{*}{$\begin{array}{l}\text { Percebe que a cooperação é } \\
\text { necessária à gestão? (3a) }\end{array}$} & Sim & 1 \\
\hline & & & Parcialmente & 0,5 \\
\hline & & & Não ou não sabe opinar & 0 \\
\hline & \multirow{3}{*}{$\begin{array}{l}\text { (4) Reconhecimento da responsa- } \\
\text { bilidade compartilhada }\end{array}$} & \multirow{3}{*}{$\begin{array}{l}\text { Reconhece a responsabilidade dos } \\
\text { demais na gestão da política? (4a) }\end{array}$} & Sim & 1 \\
\hline & & & Parcialmente & 0,5 \\
\hline & & & Não, ou não sabe opinar & 0 \\
\hline \multicolumn{4}{|c|}{ Subtotal Máximo } & 4 \\
\hline \multirow[t]{14}{*}{ Operacional } & \multirow{8}{*}{$\begin{array}{l}\text { (5) Cumprimento da responsa- } \\
\text { bilidade Nota do indicador } 5= \\
(5 a+5 b+5 c) / 3\end{array}$} & \multirow{3}{*}{$\begin{array}{l}\text { Dispõe o lixo para a coleta básica? } \\
(5 \mathrm{a})\end{array}$} & Sim, sempre & 1 \\
\hline & & & Às vezes & 0,5 \\
\hline & & & Não & 0 \\
\hline & & \multirow{3}{*}{$\begin{array}{l}\text { Faz a separação do lixo para a } \\
\text { coleta seletiva? ( } 5 b)\end{array}$} & Sim, integralmente & 1 \\
\hline & & & Alguns materiais & 0,5 \\
\hline & & & Não & 0 \\
\hline & & \multirow{2}{*}{$\begin{array}{l}\text { Procura informações sobre a GRS } \\
\text { no município? (5c) }\end{array}$} & Sim & 1 \\
\hline & & & Não & 0 \\
\hline & \multirow[t]{2}{*}{ (6) Formalização da cooperação } & \multirow{2}{*}{$\begin{array}{l}\text { Existe algum mecanismo formal } \\
\text { entre os moradores da rua/bairro/ } \\
\text { condomínio que possibilite tornar } \\
\text { a cooperação uma prática? }\end{array}$} & Sim & 1 \\
\hline & & & Não & 0 \\
\hline & \multirow{2}{*}{$\begin{array}{l}\text { (7) Instrumentos de incentivo a } \\
\text { cooperação }\end{array}$} & \multirow{2}{*}{$\begin{array}{l}\text { Há algum mecanismo de iniciativa } \\
\text { popular para estimular a coopera- } \\
\text { ção? (7a) }\end{array}$} & Sim & 1 \\
\hline & & & Não & 0 \\
\hline & \multirow[t]{2}{*}{ (8) Criatividade e experimentação } & \multirow{2}{*}{$\begin{array}{l}\text { Cria ou experimenta novas ações } \\
\text { ou estratégias para a destinação } \\
\text { dos resíduos? (8a) }\end{array}$} & Sim & 1 \\
\hline & & & Não & 0 \\
\hline \multicolumn{4}{|c|}{ Subtotal Máximo } & 4 \\
\hline
\end{tabular}




\begin{tabular}{|c|c|c|c|c|}
\hline Dimensão & Indicador & Questão-chave & Descritor & Nota \\
\hline \multirow[t]{32}{*}{ Relacional } & \multirow{8}{*}{$\begin{array}{l}\text { (9) Partilha - Cumprimento da } \\
\text { responsabilidade (sob o ponto de } \\
\text { vista dos atores governamentais). } \\
9=(9 a+9 b+9 c+9 d+9 e+9 f) / 6\end{array}$} & \multirow{3}{*}{$\begin{array}{l}\text { Dispõe o lixo para a coleta básica? } \\
\text { (9a) }\end{array}$} & Sim, sempre & 1 \\
\hline & & & Às vezes & 0,5 \\
\hline & & & Não & 0 \\
\hline & & \multirow{3}{*}{$\begin{array}{l}\text { Faz a separação do lixo para a } \\
\text { coleta seletiva? (9b) }\end{array}$} & Sim, integralmente & 1 \\
\hline & & & Alguns materiais & 0,5 \\
\hline & & & Não & 0 \\
\hline & & \multirow{2}{*}{$\begin{array}{l}\text { Procura informações sobre a GRS } \\
\text { no município? (9c) }\end{array}$} & Sim & 1 \\
\hline & & & Não & 0 \\
\hline & \multirow{8}{*}{$\begin{array}{l}\text { (9)Partilha- Cumprimento da } \\
\text { responsabilidade (sob o ponto } \\
\text { de vista dos atores econômicos). } \\
\text { Nota do indicador } 9=(9 a+9 b+9 c+- \\
9 d+9 e+9 f) / 6\end{array}$} & \multirow{3}{*}{$\begin{array}{l}\text { Dispõe o lixo para a coleta básica? } \\
\text { (9d) }\end{array}$} & Sim, sempre & 1 \\
\hline & & & Às vezes & 0,5 \\
\hline & & & Não & 0 \\
\hline & & \multirow{3}{*}{$\begin{array}{l}\text { Faz a separação do lixo para a } \\
\text { coleta seletiva? (9e) }\end{array}$} & Sim, integralmente & 1 \\
\hline & & & Alguns materiais & 0,5 \\
\hline & & & Não & 0 \\
\hline & & \multirow{2}{*}{$\begin{array}{l}\text { Procura informações sobre a GRS } \\
\text { no município? (9f) }\end{array}$} & Sim & 1 \\
\hline & & & Não & 0 \\
\hline & \multirow[t]{3}{*}{ (10) Intersetorialidade ou parceria } & $\begin{array}{l}\text { Possui alguma parceria com orga- } \\
\text { nizações ou com vizinhos, etc, para } \\
\text { tratar da questão dos RS? (10a) }\end{array}$ & Sim, parcerias efetivas e contínuas. & 1 \\
\hline & & & $\begin{array}{l}\text { Sim, parcerias ocasionais e pouco } \\
\text { efetivas. }\end{array}$ & 0,5 \\
\hline & & & Não & 0 \\
\hline & \multirow[t]{4}{*}{ (11) Comunicação } & \multirow{4}{*}{$\begin{array}{l}\text { Tem iniciativa de abrir diálogos } \\
\text { com governo ou empresas para } \\
\text { requerer, reclamar ou sugerir ações } \\
\text { (11a) }\end{array}$} & Frequentemente & 1 \\
\hline & & & Às vezes & 0,6 \\
\hline & & & Raramente & 0,3 \\
\hline & & & Nunca & 0 \\
\hline & \multirow{3}{*}{$\begin{array}{l}\text { (12) Confiança (sob o ponto de } \\
\text { vista dos atores governamentais). }\end{array}$} & \multirow{3}{*}{$\begin{array}{l}\text { Acredita que o ator específico } \\
\text { tenha boa vontade e possa se } \\
\text { esforçar para fazer sua parte? (12a) }\end{array}$} & Sim & 1 \\
\hline & & & Parcialmente & 0,5 \\
\hline & & & Não & 0 \\
\hline & \multirow{3}{*}{$\begin{array}{l}\text { (12) Confiança (sob o ponto de } \\
\text { vista dos atores econômicos) } 12= \\
(12 a+12 b) / 2\end{array}$} & \multirow{3}{*}{$\begin{array}{l}\text { Acredita que o ator específico } \\
\text { tenha boa vontade e possa se } \\
\text { esforçar para fazer sua parte? (12b) }\end{array}$} & Sim & 1 \\
\hline & & & Parcialmente & 0,5 \\
\hline & & & Não & 0 \\
\hline & \multirow[t]{3}{*}{ (13) Congruência de aspirações } & \multirow{3}{*}{$\begin{array}{l}\text { Apresenta aspirações semelhantes } \\
\text { aos demais? (13a) }\end{array}$} & Sim & 1 \\
\hline & & & Parcialmente & 0,5 \\
\hline & & & Não & 0 \\
\hline
\end{tabular}




\begin{tabular}{|c|c|c|c|c|}
\hline Dimensão & Indicador & Questão-chave & Descritor & Nota \\
\hline & \multirow[t]{6}{*}{ (14) Empoderamento e autonomia } & \multirow{3}{*}{$\begin{array}{l}\text { Reconhece que os demais exercem } \\
\text { poder na execução da política? } \\
\text { (14a) }\end{array}$} & Sim & 1 \\
\hline & & & Parcialmente & 0,5 \\
\hline & & & Não & 0 \\
\hline & & \multirow{3}{*}{$\begin{array}{l}\text { Há uma atitude de esperar pela } \\
\text { ação dos outros atores? (14b) }\end{array}$} & Não & 1 \\
\hline & & & Parcialmente & 0,5 \\
\hline & & & Sim & 0 \\
\hline \multicolumn{4}{|c|}{ Subtotal Máximo } & 6 \\
\hline \multirow{17}{*}{$\begin{array}{l}\text { Política- } \\
\text { Institucional }\end{array}$} & \multirow{3}{*}{$\begin{array}{l}\text { (15) Percepção de vantagens } \\
\text { políticas }\end{array}$} & \multirow{3}{*}{$\begin{array}{l}\text { Percebe ganhos políticos com a } \\
\text { cooperação? (15a) }\end{array}$} & Sim & 1 \\
\hline & & & Parcialmente & 0,5 \\
\hline & & & Não & 0 \\
\hline & \multirow[t]{3}{*}{ (16) Obrigações Legais } & \multirow{3}{*}{$\begin{array}{l}\text { As práticas cooperativas são } \\
\text { exclusivamente impulsionadas por } \\
\text { obrigações legais? (16a) }\end{array}$} & Não & 1 \\
\hline & & & Parcialmente & 0,5 \\
\hline & & & Sim & 0 \\
\hline & \multirow{4}{*}{$\begin{array}{l}\text { (17) Participação nos processos } \\
\text { decisórios }\end{array}$} & \multirow{4}{*}{$\begin{array}{l}\text { Participa dos espaços de tomada } \\
\text { de decisão no município? (17a) }\end{array}$} & Sempre & 1 \\
\hline & & & Às vezes & 0,6 \\
\hline & & & Raramente & 0,3 \\
\hline & & & Nunca & 0 \\
\hline & \multirow{3}{*}{$\begin{array}{l}\text { (18) Elementos institucionais para a } \\
\text { cooperação }\end{array}$} & \multirow{3}{*}{$\begin{array}{l}\text { As normas e arranjos institucionais } \\
\text { no contexto do ator possibilitam a } \\
\text { cooperação? (18a) }\end{array}$} & Sim & 1 \\
\hline & & & Parcialmente & 0,5 \\
\hline & & & Não & 0 \\
\hline & \multirow{4}{*}{$\begin{array}{l}\text { (19) Cultura institucional de } \\
\text { cooperação }\end{array}$} & \multirow{4}{*}{$\begin{array}{l}\text { Percebe que as pessoas organi- } \\
\text { zação ou de outras semelhantes } \\
\text { estão espontaneamente dispostas } \\
\text { a cooperar? (19a) }\end{array}$} & Sempre & 1 \\
\hline & & & Às vezes & 0,6 \\
\hline & & & Raramente & 0,3 \\
\hline & & & Nunca & 0 \\
\hline & & \multicolumn{2}{|l|}{ Subtotal Máximo } & 5 \\
\hline
\end{tabular}

Fonte: Elaborado pelos autores (2017) 
Diante dos princípios da PNRS, sobretudo da redução do impacto socioambiental, os indicadores e parâmetros do quadro a seguir, evidenciam o papel dos agentes econômicos na lógica da gestão compartilhada.

Quadro 5 Proposta de indicadores e parâmetros para análise dos agentes econômicos

\begin{tabular}{|c|c|c|c|c|}
\hline Dimensão & Indicador & Questão-chave & Descritor & Nota \\
\hline \multirow[t]{15}{*}{ Cognitiva } & \multirow[t]{3}{*}{ (1) Conhecimento da política } & \multirow[t]{3}{*}{ Conhece a PNRS? (1a) } & Conhece & 1 \\
\hline & & & Já ouviu falar & 0,5 \\
\hline & & & Não conhece & 0 \\
\hline & \multirow{6}{*}{$\begin{array}{l}\text { (2) Noção da problemática Nota do } \\
\text { indicador } 2=(2 a+2 b) / 2\end{array}$} & \multirow{3}{*}{$\begin{array}{l}\text { Considera a questão do lixo um } \\
\text { problema no município? (2a) }\end{array}$} & Sim, muito & 1 \\
\hline & & & Médio & 0,5 \\
\hline & & & Não ou não sabe opinar & 0 \\
\hline & & \multirow{3}{*}{$\begin{array}{l}\text { Apresenta conhecimento sobre os } \\
\text { impactos do lixo? (2b) }\end{array}$} & Sim, muito & 1 \\
\hline & & & Pouco & 0,5 \\
\hline & & & Nenhum & 0 \\
\hline & \multirow{3}{*}{$\begin{array}{l}\text { (3) Percepção da necessidade de } \\
\text { cooperação }\end{array}$} & \multirow{3}{*}{$\begin{array}{l}\text { Percebe que a cooperação é } \\
\text { necessária à gestão? (3a) }\end{array}$} & Sim & 1 \\
\hline & & & Parcialmente & 0,5 \\
\hline & & & Não ou não sabe opinar & 0 \\
\hline & \multirow{3}{*}{$\begin{array}{l}\text { (4) Reconhecimento da responsa- } \\
\text { bilidade compartilhada }\end{array}$} & \multirow{3}{*}{$\begin{array}{l}\text { Reconhece a responsabilidade dos } \\
\text { demais na gestão da política? (4a) }\end{array}$} & Sim & 1 \\
\hline & & & Parcialmente & 0,5 \\
\hline & & & Não, ou não sabe opinar & 0 \\
\hline \multicolumn{4}{|c|}{ Subtotal Máximo } & 4 \\
\hline \multirow[t]{14}{*}{ Operacional } & \multirow{8}{*}{$\begin{array}{l}\text { (5) Cumprimento da } \\
\text { responsabilidade } \\
\text { Nota do indicador } 5 \\
=(5 a+5 b+5 c) / 3\end{array}$} & \multirow{3}{*}{$\begin{array}{l}\text { Dispõe o lixo para a coleta básica? } \\
(5 a)\end{array}$} & Sempre & 1 \\
\hline & & & Às vezes & 0,5 \\
\hline & & & Nunca & 0 \\
\hline & & \multirow{3}{*}{$\begin{array}{l}\text { Faz a separação do lixo para a } \\
\text { coleta seletiva? ( } 5 b)\end{array}$} & Sim, integralmente & 1 \\
\hline & & & Alguns materiais & 0,5 \\
\hline & & & Não & 0 \\
\hline & & \multirow{2}{*}{$\begin{array}{l}\text { Organiza algum processo de logís- } \\
\text { tica reversa? }(5 c)\end{array}$} & Sim & 1 \\
\hline & & & Não & 0 \\
\hline & \multirow[t]{3}{*}{ (6) Formalização da cooperação } & \multirow{3}{*}{$\begin{array}{l}\text { Existe algum tipo de vínculo formal } \\
\text { para tornar a cooperação uma } \\
\text { prática (com outras empresas, con- } \\
\text { sumidores, organizações públicas } \\
\text { ou sociais, etc.) (6a). }\end{array}$} & Sim & 1 \\
\hline & & & Mais ou menos & 0,5 \\
\hline & & & Não & 0 \\
\hline & \multirow{3}{*}{$\begin{array}{l}\text { (7) Instrumentos de incentivo a } \\
\text { cooperação }\end{array}$} & \multirow{3}{*}{$\begin{array}{l}\text { Promove alguma ferramenta para } \\
\text { incentivar a cooperação? (7a) }\end{array}$} & Sim & 1 \\
\hline & & & Mais ou menos & 0,5 \\
\hline & & & Não & 0 \\
\hline
\end{tabular}




\begin{tabular}{|c|c|c|c|c|}
\hline Dimensão & Indicador & Questão-chave & Descritor & Nota \\
\hline & \multirow[t]{3}{*}{ (8) Criatividade e experimentação } & \multirow{3}{*}{$\begin{array}{l}\text { Cria ou experimenta novas ações } \\
\text { ou estratégias para a GRS? (8a) }\end{array}$} & Sim & 1 \\
\hline & & & Parcialmente & 0,5 \\
\hline & & & Não & 0 \\
\hline \multicolumn{4}{|c|}{ Subtotal Máximo } & 4 \\
\hline \multirow[t]{29}{*}{ Relacional } & \multirow{7}{*}{$\begin{array}{l}\text { (9) Partilha - Cumprimento da } \\
\text { responsabilidade (sob o ponto de } \\
\text { vista dos atores governamentais). }\end{array}$} & \multirow{2}{*}{$\begin{array}{l}\text { Dispõe o lixo para a coleta básica? } \\
\text { (9a) }\end{array}$} & Sim & 1 \\
\hline & & & Não & 0 \\
\hline & & \multirow{3}{*}{$\begin{array}{l}\text { Faz a separação do lixo para a } \\
\text { coleta seletiva? (9b) }\end{array}$} & Sim, integralmente & 1 \\
\hline & & & Alguns materiais & 0,5 \\
\hline & & & Não & 0 \\
\hline & & \multirow{2}{*}{$\begin{array}{l}\text { Organiza algum processo de logís- } \\
\text { tica reversa? (9c) }\end{array}$} & Sim & 1 \\
\hline & & & Não & 0 \\
\hline & \multirow{8}{*}{$\begin{array}{l}\text { (9) Partilha- Cumprimento da } \\
\text { responsabilidade (sob o ponto } \\
\text { de vista dos atores sociais). Nota } \\
\text { do indicador } 9=(9 a+9 b+9 c+- \\
9 d+9 e+9 f) / 6\end{array}$} & \multirow{3}{*}{$\begin{array}{l}\text { Dispõe o lixo para a coleta básica? } \\
\text { (9d) }\end{array}$} & Sempre & 1 \\
\hline & & & Às vezes & 0,5 \\
\hline & & & Nunca & 0 \\
\hline & & \multirow{3}{*}{$\begin{array}{l}\text { Faz a separação do lixo para a } \\
\text { coleta seletiva? (9e) }\end{array}$} & Sim, integralmente & 1 \\
\hline & & & Alguns materiais & 0,5 \\
\hline & & & Não & 0 \\
\hline & & \multirow{2}{*}{$\begin{array}{l}\text { Organiza algum processo de logís- } \\
\text { tica reversa? ( } 9 f \text { ) }\end{array}$} & $\operatorname{Sim}$ & 1 \\
\hline & & & Não & 0 \\
\hline & \multirow[t]{3}{*}{ (10) Intersetorialidade ou parceria } & \multirow{3}{*}{$\begin{array}{l}\text { Possui alguma parceria com outras } \\
\text { organizações para tratar da ques- } \\
\text { tão dos resíduos sólidos? (10a) }\end{array}$} & Existe & 1 \\
\hline & & & Está em andamento & 0,5 \\
\hline & & & Não existe & 0 \\
\hline & \multirow[t]{2}{*}{ (11) Comunicação } & \multirow{2}{*}{$\begin{array}{l}\text { Possui algum canal de comunica- } \\
\text { ção aberto aos clientes e organiza- } \\
\text { ções públicas? (11a) }\end{array}$} & $\operatorname{Sim}$ & 1 \\
\hline & & & Não & 0 \\
\hline & \multirow{3}{*}{$\begin{array}{l}\text { (12) Confiança (sob o ponto de } \\
\text { vista dos atores sociais). }\end{array}$} & \multirow{3}{*}{$\begin{array}{l}\text { Acredita que o ator específico } \\
\text { tenha boa vontade e possa se } \\
\text { esforçar para fazer sua parte? (12a) }\end{array}$} & Sim & 1 \\
\hline & & & Parcialmente & 0,5 \\
\hline & & & Não & 0 \\
\hline & \multirow{3}{*}{$\begin{array}{l}\text { (12) Confiança (sob o ponto de } \\
\text { vista dos atores governamentais) }\end{array}$} & \multirow{3}{*}{$\begin{array}{l}\text { Acredita que o ator específico } \\
\text { tenha boa vontade e possa se } \\
\text { esforçar para fazer sua parte? (12b) }\end{array}$} & $\operatorname{Sim}$ & 1 \\
\hline & & & Parcialmente & 0,5 \\
\hline & & & Não & 0 \\
\hline & \multirow[t]{3}{*}{ (13) Congruência de aspirações } & \multirow{3}{*}{$\begin{array}{l}\text { Apresenta aspirações semelhantes } \\
\text { aos demais? (13a) }\end{array}$} & $\operatorname{Sim}$ & 1 \\
\hline & & & Parcialmente & 0,5 \\
\hline & & & Não & 0 \\
\hline
\end{tabular}




\begin{tabular}{|c|c|c|c|c|}
\hline Dimensão & Indicador & Questão-chave & Descritor & Nota \\
\hline & \multirow{6}{*}{$\begin{array}{l}\text { (14) Empoderamento e autonomia } \\
\text { Nota do indicador } 14=(14 a+14 b) 2\end{array}$} & \multirow{3}{*}{$\begin{array}{l}\text { Reconhece que os demais exercem } \\
\text { poder na execução da política? } \\
\text { (14a) }\end{array}$} & Sim & 1 \\
\hline & & & Parcialmente & 0,5 \\
\hline & & & Não & 0 \\
\hline & & \multirow{3}{*}{$\begin{array}{l}\text { Há uma atitude de esperar pela } \\
\text { ação dos outros atores? (14b) }\end{array}$} & Não & 1 \\
\hline & & & Parcialmente & 0,5 \\
\hline & & & Sim & 0 \\
\hline \multicolumn{4}{|c|}{ Subtotal Máximo } & 6 \\
\hline \multirow{17}{*}{$\begin{array}{l}\text { Política- } \\
\text { Institucional }\end{array}$} & \multirow{3}{*}{$\begin{array}{l}\text { (15) Percepção de vantagens } \\
\text { políticas }\end{array}$} & \multirow{3}{*}{$\begin{array}{l}\text { Percebe ganhos políticos com a } \\
\text { cooperação? (15a) }\end{array}$} & Sim & 1 \\
\hline & & & Parcialmente & 0,5 \\
\hline & & & Não & 0 \\
\hline & \multirow[t]{3}{*}{ (16) Obrigações Legais } & \multirow{3}{*}{$\begin{array}{l}\text { As práticas cooperativas são } \\
\text { exclusivamente impulsionadas por } \\
\text { obrigações legais? (16a) }\end{array}$} & Não & 1 \\
\hline & & & Parcialmente & 0,5 \\
\hline & & & Sim & 0 \\
\hline & \multirow{4}{*}{$\begin{array}{l}\text { (17) Participação nos processos } \\
\text { decisórios }\end{array}$} & \multirow{4}{*}{$\begin{array}{l}\text { Participa dos espaços de tomada } \\
\text { de decisão no município? (17a) }\end{array}$} & Sempre & 1 \\
\hline & & & Às vezes & 0,6 \\
\hline & & & Raramente & 0,3 \\
\hline & & & Nunca & 0 \\
\hline & \multirow{3}{*}{$\begin{array}{l}\text { (18) Elementos institucionais para a } \\
\text { cooperação }\end{array}$} & \multirow{3}{*}{$\begin{array}{l}\text { As normas e arranjos institucionais } \\
\text { no contexto do ator possibilitam a } \\
\text { cooperação? (18a) }\end{array}$} & Sim & 1 \\
\hline & & & Parcialmente & 0,5 \\
\hline & & & Não & 0 \\
\hline & \multirow[t]{4}{*}{ (19) Cultura de cooperação } & \multirow{4}{*}{$\begin{array}{l}\text { Percebe que as pessoas da orga- } \\
\text { nização ou de outras semelhantes } \\
\text { estão espontaneamente dispostas } \\
\text { a cooperar? (19a) }\end{array}$} & Sempre & 1 \\
\hline & & & Às vezes & 0,6 \\
\hline & & & Raramente & 0,3 \\
\hline & & & Nunca & 0 \\
\hline \multicolumn{4}{|c|}{ Subtotal Máximo } & 5 \\
\hline
\end{tabular}

Fonte: Elaborado pelos autores (2017)

Alguns indicadores, como o (12) e o (9), foram preparados para serem preenchidos com informações fornecidas pelos atores concorrentes, por exemplo: a informação sobre a confiança nas ações dos agentes governamentais será respondida pelos agentes econômicos e agentes sociais, porém a pontuação será feita na matriz dos agentes governamentais. Isso se justifica pelo pressuposto de que os atores tendem a enaltecer as suas práticas, sendo assim, indispensável o ponto de vista dos outros envolvidos.

\subsection{Proposta de avaliação em níveis de cooperação}

Apesar de todas as dimensões da cooperação serem substanciais para a sua promoção, no plano prático, ou seja, na concretização da ação humana, as práticas contempladas nos indicadores da dimensão operacional traduzem com mais diligência a cooperação no âmbito da gestão, isso porque abarcam simultaneamente a motivação, a percepção e a ação de cooperar. Por conta disso, é essencial que se empregue pesos na medida de avaliação, colocando maior 
peso para o subtotal da dimensão operacional. Outra motivação para o uso de pesos é disparidade na quantidade de indicadores por dimensão, que pode levar a uma distorção, caso não haja uma ponderação. Segue no QUADRO 6 a indicação dos pesos por dimensão.

Quadro 6 Pesos das dimensões

\begin{tabular}{l|l}
\multicolumn{1}{c|}{ Dimensão } & \multicolumn{1}{c}{ Peso } \\
\hline Cognitiva (DC) & 1 \\
\hline Operacional (DO) & 1,7 \\
\hline Relacional (DR) * & 0,7 \\
\hline Político-Institucional (DPI) * & 0,8 \\
\hline
\end{tabular}

* Apresentaram um menor peso não porque tem menos importância, mas pela justificativa da desigualdade na quantidade de indicadores.

Fonte: Elaborado pelos autores (2017)

Após a ponderação das notas dos agentes em relação ao peso da dimensão, deve-se aplicar as equações abaixo para que se chegue nos níveis de cooperação por localidade, ou por agente, como demonstrado nos QUADROS 7 e 8, respectivamente.

Quadro 7 Classificação do nível de cooperação local

\begin{tabular}{c|c}
\hline Intervalo & $\begin{array}{c}\text { Nível de cooperação entre os agentes } \\
\text { na gestão compartilhada local }\end{array}$ \\
\hline 0 & Sem cooperação \\
\hline $1,0 \leq X \leq 4,0$ & Baixo nível de cooperação \\
\hline $5,0 \leq X \leq 8,0$ & Médio nível de cooperação \\
\hline $9,0 \leq X \leq 10$ & Alto nível de cooperação \\
\hline
\end{tabular}

Fonte: Elaborado pelos autores (2017)

$$
X=\frac{\sum \text { das notas de cada agente após ponderação por dimensão }}{\sum \text { da pontuação máxima para cada agente }} \times 10
$$

Quadro 8 Classificação do nível de cooperação por agente

\begin{tabular}{c|c}
\hline Intervalo & Nível de cooperação individual do agente \\
\hline 0 & Não coopera \\
\hline $1,0<X<4,0$ & Baixo \\
\hline $5,0<X<8,0$ & Razoável \\
\hline $9,0<X<10$ & Alto \\
\hline
\end{tabular}

Fonte: Elaborado pelos autores (2017)

O denominador da equação 1 será de 57 no caso de ser possível atribuir notas a todos os indicadores para cada um dos agentes. Assim, o X ficará dentro de uma das faixas descritas no QUADRO 7. O mesmo caso se aplica à equação 2 , mas o denominador será de 19 no caso de ser possível atribuir notas a todos os 
indicadores referentes ao agente avaliado. No caso de demonstrações parciais para cada dimensão, a lógica da métrica é a mesma.

\subsection{Recomendações para o levantamento de dados}

Os indicadores propostos acima têm uma finalidade avaliativa, como plano de tratamento das informações, portanto, precede uma coleta de dados. É evidente a necessidade de uma mescla de fontes de dados, o que pressupõe o uso de diferentes técnicas de coleta. A aplicação de questionários ou realização de entrevistas emergem como opções que conseguem coletar a maior quantidade de dados, já que a maior parte dos indicadores depende de declaração dos sujeitos centrais. A pesquisa documental ou de dados secundários é uma opção complementar, para corroboração de informações ou de dados que não surgiram durante a pesquisa de campo.

$\mathrm{Na}$ fase de levantamento de dados, o pesquisador/ avaliador tem a liberdade para construir seu roteiro, no sentido de conduzir a pesquisa pelo caminho mais eficiente. Cabe lembrar que para a definição dos atores sociais e econômicos são necessários cálculos de amostragem para a composição do quadro de respondentes, bem como o uso de estatística descritiva para a definição das respostas/notas finais.

\section{CONSIDERAÇÕES FINAIS}

Os indicadores propostos contemplam diferentes níveis de como a cooperação pode ocorrer e como pode ser promovida no âmbito das políticas públicas. Fornecem aos gestores uma visão mais clara sobre a estrutura de gestão compartilhada de resíduos sólidos, permitindo que possam ser planejadas ações pontuais a fim de garantir a parceria entre os setores. Para os pesquisadores, tais indicadores abrem caminhos para novas possibilidades de estudos empíricos, tendo em vista o alto grau de adaptabilidade para outras questões igualmente relevantes.

Quando utilizados como mecanismo de avaliação, os indicadores são capazes de exibir à sociedade o quão importante é o seu engajamento nos espaços político-administrativos. Assim como defende Axelrod
(1986), a cooperação deve ser ensinada às pessoas, e através de instrumentos de educação ambiental é que essa prática específica pode se tornar culturalmente difundida, tendo como consequência uma maior efetividade nas ações e nos meios de execução dos planos de gestão de resíduos sólidos.

Com em qualquer outro tipo de avaliação ou análise de políticas públicas, alguns gargalos podem aparecer. Um dos principais, que geralmente aflige a pesquisa social é a disponibilidade e o compromisso dos respondentes, que limitam a completude dos dados e como corolário comprometem os resultados da avaliação. Esclarecer bem o propósito do estudo e suas possíveis vantagens é um caminho interessante para sanar tais dificuldades.

Em relação ao compartilhamento de responsabilidades na gestão de políticas públicas, as dimensões e os indicadores revelam que essa prática abrange uma infinidade de fatores que vão além da estrutura administrativa, pois envolve comportamentos, culturas, fatores políticos e capacidades técnicas. Mesmo sabendo da complexidade, as inovações e novas tendências em gestão pública caminham no intuito de tornar a cooperação e gestão compartilhada como práticas difundidas.

\section{REFERÊNCIAS}

ABRUCIO, F.L; FILIPPIN, E. S.; DIEGUEZ, R. C. Inovação na cooperação intermunicipal no Brasil: a experiência da Federação Catarinense de Municípios (Fecam) na construção de consórcios públicos. Revista de Administração Pública, v.47 n.6, pp. 1543-568, 2013. Disponível em: http:// bibliotecadigital.fgv.br/ojs/index.php/rap/article/ view/13987/12873

AXELROD, R. La evolución de la cooperación In: AXELROD, R. La evolución de la cooperación: el dilema del prisionero y la teoria de juegos. Madrid: Alianza, 1986. 
BRANDÃO, E. J; OLIVEIRA, J.G. A Logística Reversa como instrumento da gestão compartilhada na atual Política Nacional de Resíduos Sólidos. Revista do Curso de Direito da UNIABEU, v.2 n.2, pp. 19-36, 2012. Disponível em: http://www.uniabeu.edu.br/ publica/index.php/rcd/article/view/952

BRASIL, (2010) Lei no 12.305, de 2 de Agosto de 2010. Institui a Política Nacional de Resíduos Sólidos; altera a Lei no 9.605, de 12 de fevereiro de 1998 e dá outras providências. Brasilia: Palácio do Planalto, 2015.

COSTA, F. L.; CASTANHAR, J. Avaliação de programas públicos: desafios conceituais e metodológicos. Revista de Administração Pública, v. 37 n. 22, pp.969-992, 2003. Disponível em: http://bibliotecadigital.fgv.br/ojs/index.php/rap/article/view/6509/5093

DAHL, R. A. Poliarquia: Participação e Oposição. São Paulo: EDUSP, 1997.

DEMAJOROVIC, J. ; BESEN, G. R. ; RATHSAM, A. A. Gestão compartilhada de resíduos sólidos face à lógica de mercado. In: ENCONTRO DA ASSOCIAÇÃO NACIONAL DE PÓS-GRADUAÇÃO E PESQUISA EM AMBIENTE E SOCIEDADE, 2004, Indaiatuba. I, Anais. Indaiatuba: ANPPAS.

FLEURY, S.; OUVERNEY, A. M. Gestão de redes: a estratégia de regionalização da política de saúde. Rio de Janeiro: FGV, 2007.

HAWKINS, C. Competition and cooperation: local government joint ventures for economic development. Journal of Urban Affairs, v. 32 n. 2, pp. 253-275, 2010. doi: 10.1111/j.1467-9906.2009.00492.x

HEBER, F.; SILVA, E. M. da. Institucionalização da Política Nacional de Resíduos Sólidos: dilemas e constrangimentos na Região Metropolitana de Aracaju (SE). Revista de Administração Pública , v. 48 n. 4, pp. 913-937. 2014. Disponível em: http://www.scielo. br/pdf/rap/v48n4/a06v48n4.pdf.

INSTITUTO ETHOS. Política Nacional de Resíduos Sólidos: Desafios e Oportunidades para as Empresas. São Paulo, 2012.
JANNUZZI, P.D.M. Indicadores para Diagnóstico, Monitoramento e Avaliação de Programas Sociais no Brasil. Revista do Serviço Público, v.56 n.2, pp.137-160, 2005. Disponível em: http://camara.fecam.org.br/uploads/28/arquivos/4054_JANUZZI_P_ Construcao_Indicadores_Sociais.pdf

KOLK, A. From conflict to cooperation: international policies to protect the Brazilian Amazon. World Development, v.26, n.8, pp.1481-93, 1998. doi: 10.1016/S0305-750X(98)00062-X.

LUNDIN, M. When Does Cooperation Improve Public Policy Implementation? The Policy Studies Journal, v. 35 n. 4, 2007a. doi: 10.1111/j.1541-0072.2007.00240.x.

LUNDIN, M. Explaining cooperation: how resource interdependence, goal congruence, and trust affect joint actions in policy implementation. Journal of Public Administration Research and Theory, v.17, n.4, pp.651-672, 2007 (b).

MATTIA, C.; ZAPPELLINI, M. Ética e coprodução de serviços públicos: uma fundamentação a partir de Habermas. Cadernos EBAPE, v.12, n.3, pp. 573 589, 2014. Disponível em: http:// www.scielo.br/scielo.php? script $=$ sci_arttex t\&pid=S1679-39512014000300003.

MATUdA, C.; AGUIAR, D. M. L; FRAZÃO, P. Cooperação interprofissional e a Reforma Sanitária no Brasil: implicações para o modelo de atenção à saúde. Saúde e Sociedade v.22, n.1, pp.173-86, 2013. Disponível em: http:// www.scielo.br/scielo.php?script=sci_arttext\&pid=S0104-12902013000100016.

MINAYO, M.C.D.S. Construção de indicadores qualitativos para avaliação de mudanças. Revista Brasileira de Educação Médica, v. 33(supl. 1), pp. 83-91, 2009. Disponível em: http://www.scielo.br/ scielo.php?pid=S0100-55022009000500009\&scri $\mathrm{pt}=\mathrm{sci} \_$abstract\&tlng=pt. 
MOREIRA, D. A. Responsabilidade ambiental pós-consumo: prevenção e reparação de danos à luz do princípio do poluidor-pagador. Tese (Doutorado em Direito da Cidade), Universidade do Estado do Rio de Janeiro. Rio de Janeiro, 2008.

MOTTA, F. C. P.; VASCONCELOS, I. F. G. Teoria geral da Administração. 3 ed. São Paulo: Thomson, 2006.

MUNHOZ, W.A.; FERREIRA, A.A. A cooperação em rede como fator de eficácia organizacional na gestão da coleta de resíduos sólidos domiciliares no município de Santo André. Revista Desenvolvimento e Meio Ambiente, v. 26, pp. 199-214, 2012. Disponível em: http://revistas.ufpr. br/made/article/view/27080/19680.

ORSI, R. A. Gestão participativa dos resíduos sólidos urbanos. $136 \mathrm{f}$. Dissertação (Mestrado em Geografia)- Universidade Estadual Paulista. Rio Claro, 2006.

RIBEIRO, R. de M.; SALM, J.; MENEGASSO, M. E. Co-produção do bem público e o desenvolvimento da cidadania: o caso do PROERD em Santa Catarina. Revista Alcance, v.14, n. 2, pp. 231-246, 2007. Disponível em: http://siaiap32.univali.br/seer/index. $\mathrm{php} / \mathrm{ra} /$ article/view/106/84

RING, P.S.; VAN DE VEN, A.H. Developmental processes of cooperative interorganisational relationships. Academy of Management Review, v.19, n.1, pp. 90-118, 1994.

ROCHA, C.V.; FARIAS, C.A.P. de. Cooperação intermunicipal, reterritorialização da gestão pública e provisão de bens e serviços sociais no Brasil contemporâneo: a experiência dos Consórcios de Saúde de Minas Gerais. Cadernos Metrópole, v.11, n.1, pp. 73-105, 2004. Disponível em: http://revistas.pucsp.br/ index.php/metropole/article/view/8815/6536.

ROMANI, A. P. de; SEGALA, K. Planos de resíduos sólidos: desafios e oportunidades no contexto da Política Nacional de Resíduos Sólidos. Rio de Janeiro: IBAM, 2014.
SANTIAGO, L.S.; DIAS, S.M.F. Matriz de indicadores de sustentabilidade para a gestão de resíduos sólidos urbanos. Engenharia Sanitária Ambiental, v.17, n.2, pp. 203-212, 2012. Disponível em: http://www.scielo. br/pdf/esa/v17n2/a10v17n2.pdf.

SMITH, K. G; CARROLL, S. J.; ASHFORD, S. J. Intra- and interorganizational cooperation: Toward a research agenda. Academy of Management Journal, v. 38, pp. 7-23, 1995.

SOUZA, C. Políticas públicas: uma revisão da literatura. Sociologias, v. 16 n. 1, pp. 20-45, 2006. Disponível em: http://www.scielo.br/scielo.php?script=sci_arttext\&pid=S1517-45222006000200003 .

WEISS, J. Pathways to Cooperation among Public Agencies. Policy Analysis and Management, v.7, n.1, pp. 94-117, 1987.

WHITAKER, G.P. Coproduction: Citizen Participation in Service Delivery. Public Administration Review, v.40, n.3, pp. 240-246, 1980. doi: 10.2307/975377. 